\title{
A AÇÃo POLÍtica do MST
}

Bruno Konder Comparato

Cientista Político, Doutorando na FFLCH-USP

\begin{abstract}
Resumo: Estudo do Movimento dos Trabalhadores Rurais Sem Terra (MST) como ator político. A partir de uma ampla pesquisa em material jornalístico, verificou-se que o MST conquistou um espaço político importante no quadro público atual, contrariando toda uma suposta tradição de passividade e anomia do povo brasileiro, ao conseguir se organizar, ter força política e desafiar os poderes constituídos.

Palavras-chave: reforma agrária; MST; ator político.
\end{abstract}

$\mathrm{E}$ m reação à ocupação da sua fazenda pelo Movimento dos Trabalhadores Rurais Sem Terra (MST), em abril de 2001, o embaixador do Brasil na Itália, Paulo Tarso Flecha de Lima, comentou que o objetivo da invasão era político e sem justificativa fundiária e social. De maneira semelhante, o ministro do Desenvolvimento Agrário, Raul Jungmann, acusou o MST de agir politicamente e se recusou a receber o movimento (O Estado de S.Paulo, 03/04/2001; Folha de S.Paulo, 05/ 04/2001). Essas reações são significativas porque mostram que o governo brasileiro considera o MST um grupo que atua de forma política. Mas elas ilustram também a tática do governo de desqualificar constantemente esse movimento e dificultar as negociações.

Em um país de dimensões continentais como o Brasil, no qual a maioria dos partidos políticos é tradicionalmente fraca e regionalizada, os outros atores políticos não podem ser negligenciados. Principalmente quando estão presentes em escala nacional, caso do MST. Deve-se prestar especial atenção aos grupos que estabelecem uma novidade no cenário político nacional. Pode-se dizer que o MST constitui um ator político novo, mesmo que nenhuma de suas ações ou características organizativas seja original. A novidade está na articulação, feita a partir de táticas e elementos já conhecidos, e na habilidade política que o movimento tem demonstrado, ao fazer aliados em vários segmentos da sociedade civil. Trata-se de uma for- ma diferente de reivindicação social, ou, se preferirmos, de uma nova forma de atuação política.

A partir de uma ampla pesquisa em material jornalístico, verifica-se que o MST conquistou um espaço político importante no quadro público atual, e, contrariando toda uma suposta tradição de passividade e anomia do povo brasileiro, consegue se organizar, ter força política e desafiar os poderes constituídos. Uma análise detalhada do relacionamento entre o MST e o governo, o Congresso, a imprensa, a Igreja e a opinião pública, revelou que o movimento cresceu e se expandiu durante a presidência de Fernando Henrique Cardoso, e não pode mais ser ignorado.

\section{O MST E A LUTA PELA TERRA}

O MST surgiu da reunião de vários movimentos populares de luta pela terra, os quais promoveram ocupações de terra nos Estados do Rio Grande do Sul, Santa Catarina, Paraná, São Paulo e Mato Grosso do Sul, na primeira metade da década de 80 . Oficialmente, o MST foi fundado em janeiro de 1984, na cidade de Cascavel, no Estado do Paraná, por ocasião do Primeiro Encontro Nacional do Movimento dos Trabalhadores Rurais Sem Terra, com 80 representantes de 13 Estados. Atualmente, o movimento está presente em 23 dos 26 Estados da federação, e é capaz de organizar manifestações em duas dezenas de capitais simultaneamente. Pelas últimas estimativas, os efeti- 
vos do MST se elevam a 350 mil famílias assentadas e 70 mil famílias em acampamentos, o que representa cerca de 1,5 milhão de pessoas.

Naturalmente, o MST não é o primeiro movimento de luta pela terra. Na história do Brasil há vários relatos de revoltas camponesas. Todos os movimentos anteriores, contudo, permaneceram limitados à região em que surgiram. A ação das Ligas Camponesas, nos anos 60 concentrou-se no Estado de Pernambuco e adjacências. O mesmo aconteceu com Canudos, no final do século XIX, e com o Contestado, no começo do século XX, que ficaram restritos ao nordeste da Bahia e ao oeste catarinense. Além disso, tanto em Canudos quanto no Contestado, os revoltosos eram animados por aspectos messiânicos e místicos, e ansiavam mais por um retorno ao passado do que por uma transformação do presente (Candido, 1998; Cunha, 1979; Martins, 1995; Monteiro, 1974; Queiroz, 1965 e 1977). Outra característica importante destaca o MST de todos os movimentos anteriores de luta pela terra: trata-se do primeiro movimento que identifica como seu principal adversário o governo federal, e não os grandes proprietários de terras.

Faz-se necessário lembrar, também, que o MST não é o único movimento de luta pela reforma agrária. Existem atualmente dezenas de outros movimentos, inspirados no MST ou dissidências dele, como os próprios nomes sugerem, por exemplo, o MAST (Movimento dos Agricultores Sem Terra), ligado à Social Democracia Sindical, o MLST (Movimento de Libertação dos Sem Terra), ligado a segmentos da esquerda, e o MUST (Movimento Unido dos Sem Terra), ligado à Força Sindical. Os dados reunidos por Bernardo Mançano Fernandes (1999) mostram que o MST é responsável por apenas um terço das ocupações de terras realizadas no Brasil desde 1996, e representa aproximadamente dois terços das famílias acampadas recenseadas desde aquele ano. Esses outros movimentos de luta pela terra disputam, portanto, o mesmo espaço político que o MST. A leitura cotidiana do noticiário político revela, contudo, que o maior adversário do governo nesse campo é o MST.

\section{O MST E O GOVERNO}

Para se ter uma idéia da força política conquistada pelo MST durante o governo de Fernando Henrique Cardoso, basta verificar a evolução da atenção que o governo federal tem dispensado ao movimento. Em 1994, ainda no governo de Itamar Franco, a Folha de S.Paulo informava que o Instituto Nacional de Colonização e Reforma Agrária (Incra) não sabia quantas invasões tinham sido efetivadas nos anos anteriores (Folha de S.Paulo, 05/04/94). Cinco anos mais tarde, as informações sobre o MST passaram a ser sistematicamente compiladas por um "gabinete de crises", ligado ao Gabinete de Segurança Institucional (GSI) da Presidência da República, e instalado no quarto andar do Palácio do Planalto. Num grande mapa são periodicamente registradas as áreas ocupadas, os acampamentos, as escolas de formação de militantes e até as dissidências do MST (Valor, 09/06/2000). Faz-se necessário ressaltar que, entre essas duas datas, dois acontecimentos importantes obrigaram o governo a dedicar maior atenção ao MST: o massacre de Eldorado dos Carajás, ocorrido em 17 de abril de 1996, e a Marcha a Brasília, realizada de fevereiro a abril de 1997. Com efeito, apesar de ter incluído a reforma agrária no plano de governo anunciado durante a campanha eleitoral ( $O$ Globo, 06/07/97), de ter afirmado que "a base da política fundiária do meu governo é a reforma agrária" (Folha de S.Paulo, 24/03/95), e de ter anunciado a intenção de dialogar com o MST em audiência, em 27 de julho de 1995, o Presidente da República não percebeu imediatamente a gravidade do massacre de Eldorado dos Carajás, em que 19 militantes do MST foram mortos pela polícia militar do Pará.

Exatamente uma semana antes, ao comentar para a rede de notícias americana $C N N$ a ocupação simultânea de locais de grande movimento em 18 capitais do País, por dez mil agricultores coordenados pelo MST, no dia 10 de abril de 1996, Fernando Henrique Cardoso demonstrava a pouca importância que seu governo atribuía ao MST até então. Em artigo publicado na revista Istoé (17/04/96), lê-se: “A direção nacional do MST também quer audiência com o presidente FHC. Toda a movimentação obteve repercussão internacional, ao ser mostrada pela rede $C N N$. Questionado por um correspondente da emissora no País, FHC disse que seu governo está preocupado, mas não pelo tamanho da marcha de quarta-feira. 'O Brasil é um país urbano e temos mais de $75 \%$ da população nas cidades. Esses são problemas localizados', reagiu.". No dia seguinte ao massacre de Eldorado dos Carajás, o presidente procurou minimizar o problema: "os sem-terra e a polícia militar são representantes do Brasil arcaico". Alertado por assessores, e atento à repercussão internacional, o presidente foi obrigado a mudar o tom. Novamente na revista IstoÉ (24/04/96), lê-se: "No dia seguinte à chacina, o presidente (...) classificou de 'representantes do Brasil arcaico' os sem-terra e a polícia. (...) $\mathrm{Na}$ tarde de quinta-feira, 
18, de olho na repercussão internacional atingida pela matança, o presidente resolveu ele próprio conceder uma entrevista coletiva no Palácio do Planalto. (...) Em 1996, o governo ainda não assentou nenhuma família.". No dia 18 de abril, um dia depois do massacre de Eldorado dos Carajás, o ministro da Agricultura José Eduardo Andrade Vieira, proprietário de grandes extensões de terras, foi destituído. Logo em seguida, o Ministério da Agricultura foi desmembrado, com a recriação do Ministério da Reforma Agrária, que tinha sido extinguido ao final do governo Sarney, com Raul Jungmann como titular da pasta.

A postura do governo diante do MST mudou após o massacre de Eldorado dos Carajás. Fernando Henrique Cardoso percebeu a necessidade de coordenar melhor as ações para poder enfrentar o movimento. Essa mudança foi percebida pelos meios de comunicação: "O governo resolveu adotar uma linha mais dura para enfrentar o MST. O objetivo é impedir não apenas as invasões de sedes do Incra, como o MST vem fazendo nas grandes cidades, mas também a ocupação de fazendas, ação preferencial dos sem-terra. A proposta aprovada na reunião foi coordenar a repressão ao MST no Gabinete Militar da Presidência, em vez de deixar a tarefa para os governadores de Estado, como aconteceu até a semana passada. Toda vez que se verificar que as polícias militares não estão dando conta dos conflitos, tropas do Exército serão chamadas." (Veja, 26/06/96). De fato, o general Alberto Mendes Cardoso, chefe da Casa Militar do Palácio do Planalto, passou a supervisionar diariamente as atividades do MST, como informa outro artigo da revista Veja (23/04/97). Foi no exercício dessa nova função que ele visitou Eldorado dos Carajás, assim como sete acampamentos em áreas de conflito. A revista informa ainda que o general controlava 900 homens, em 12 agências regionais de inteligência, e produzia um relatório que, durante os dois meses de duração da marcha do MST a Brasília, em 1997, era enviado diariamente ao presidente. Mesmo com toda essa organização, o governo subestimou a capacidade do MST de realizar uma marcha de dois meses até Brasília. Esse mesmo artigo sustenta que o ministro da Reforma Agrária, Raul Jungmann, convenceu Fernando Henrique Cardoso a aceitar receber as lideranças do MST com o argumento de que a Marcha a Brasília fracassaria e o encontro não seria realizado. "Até a chegada da marcha, o Planalto achava que a questão da terra tinha sido artificialmente inflada pelo massacre de Eldorado dos Carajás e pela novela O Rei do Gado. (...) Depois de um clamoroso erro de cálculo e de educação política, de desprezar o poder de mobilização dos sem-terra, de falar de 'primitivismo' e de 'utopia regressiva' mesmo quando as pesquisas de opinião informavam que $80 \%$ da população queria a reforma agrária, o governo sentou-se à mesa para conversar." (Veja, 23/04/97).

Seja como for, o despreparo do governo para lidar com a questão agrária é claro. A seguinte frase, que segundo a revista Veja teria sido pronunciada pelo ministro Raul Jungmann, por exemplo, não é exatamente o que se esperaria de um ministro da Reforma Agrária: "O MST é um movimento numericamente pequeno. Está trazendo 1.500 pessoas para Brasília. O Rotary e o Lions têm muito mais gente." (Veja, 23/04/97). Essa reação somente pode ser compreendida quando se leva em conta que uma das estratégias do governo ao lidar com o MST é desqualificálo e buscar constantemente diminuir a importância e o alcance de suas ações.

Outra linha de conduta adotada pelo governo, para enfrentar a pressão exercida pelo MST, é tentar descaracterizá-lo como movimento social, para enquadrá-lo como um movimento criminoso, que realiza um conjunto de ações fora da lei. A partir desse ponto de vista, torna-se possível compreender como um ministro da Justiça, no caso, Iris Rezende, pôde afirmar, numa reunião com secretários de segurança de vários Estados, que: "Polícia e fazendeiros têm de andar de mãos dadas para cumprir mandados judiciais." (Veja, 24/09/97). Nessa mesma ocasião, de acordo com a revista Veja, o ministro da Justiça disse estar arrependido de não ter apoiado a polícia do Pará no episódio de Eldorado dos Carajás.

Como mostram esses exemplos, as principais estratégias do governo para combater o MST não enfrentam diretamente o movimento, mas buscam atingir a sua imagem e popularidade junto à opinião pública. De modo análogo, as análises dos discursos oficiais, das falas do Presidente da República e de seus representantes, fazem perceber que o governo evita referir-se diretamente ao MST.

Ao iniciar o seu primeiro governo, Fernando Henrique Cardoso acreditava que esvaziaria o MST fazendo alguns assentamentos. O raciocínio era o seguinte: a média histórica de desapropriações de terra que deram origem a assentamentos para a reforma agrária no Brasil sempre foi muito pequena. De acordo com os dados do governo, era de 12 mil famílias assentadas por ano. Os analistas do governo estimaram ser possível assentar 40 mil famílias em 1995, 60 mil em 1996, 80 mil em 1997 e 100 mil em 1998, totalizando, assim, 280 mil famílias assentadas em quatro anos. Caso esse plano fosse executado com sucesso, de 
um lado, os movimentos de trabalhadores sem terra se esvaziariam por falta de militantes, e, de outro, a perda de legitimidade que essa questão levantaria na opinião pública, à medida que as reivindicações fossem sendo atendidas.

A análise dos pronunciamentos do Presidente da República que abordam a reforma agrária indica que, se num primeiro momento o governo se mostrava favorável à reforma agrária, evitando, contudo, referir-se diretamente ao MST, Fernando Henrique Cardoso foi progressivamente se dirigindo de forma cada vez mais explícita ao MST, que passou a ser tratado como adversário. Até que, a partir de maio de 2000, quando o movimento promoveu manifestações e ocupações de prédios públicos em quase todos os Estados, o governo adota um tom mais duro para se referir ao MST, deixando claro que, no seu ponto de vista, o movimento tem exagerado.

Os encontros entre o Presidente da República e representantes do MST também são importantes, pois é a partir deles que tanto o governo quanto o movimento se reconhecem mutuamente como interlocutores políticos. A partir do momento em que estabelecem um diálogo, por mais truncado que seja, eles se reconhecem como adversários, mesmo em campos opostos, e não como inimigos. Com efeito, para ambos seria um erro estratégico pretender eliminar o outro, pois o MST precisa do governo, da mesma forma que o governo não pode ignorar o MST. Os dirigentes do movimento têm plena consciência de que precisam da mediação do governo para atingir os seus objetivos. Apenas o governo pode desapropriar terras, conceder indenizações, garantir crédito aos assentados, estabelecer uma política agrária e executá-la. Em outras palavras, o governo é o único ator que pode conciliar os interesses em jogo e impedir que o conflito entre os proprietários de terra e os sem-terra se radicalize. Por outro lado, sem a presença do MST, o número de mortes no campo seria, provavelmente, muito maior. A morte de um militante do MST é muito mais constrangedora para o governo do que o assassinato de um trabalhador rural não pertencente ao movimento. Qualquer ação na qual esteja envolvido o MST adquire mais visibilidade do que outras, nem que seja pelo fato de ser automaticamente considerada um ato de desafio ao governo. Por essa razão é que podemos afirmar que o governo não pode ignorar o MST, e deve sempre levar em conta a resposta do movimento quando estabelece sua política agrária.

De 1995 até o final de 2000, foram realizados cinco encontros importantes entre Fernando Henrique Cardoso e o MST. De maneira geral, o movimento está sempre disposto a dialogar com o Presidente da República. Nota-se, contudo, que na maioria dos casos as audiências podem ser relacionadas com acontecimentos importantes, como a primeira delas, que ocorreu em 27 de julho de 1995, por ocasião do $3^{\circ}$ Congresso Nacional do MST, ou com situações em que o movimento desafia o governo e o obriga a negociar. Os encontros realizados em 2 de maio de 1996 e 18 de abril de 1997, por exemplo, estão relacionados com o massacre de Eldorado dos Carajás e a Marcha a Brasília. Houve, em seguida, uma reunião em 8 de julho de 1999 e outra em 3 de julho de 2000, diante da ameaça de ocupação da fazenda da família de Fernando Henrique Cardoso, em Minas Gerais.

As reivindicações apresentadas pelo MST durante esses encontros são muitas. Todas elas poderiam, contudo, ser resumidas em apenas dois itens: o assentamento das famílias acampadas e a concessão de créditos para possibilitar a produção das famílias assentadas. Os valores envolvidos nessa discussão são consideráveis, da ordem de um ou dois milhões de reais anuais.

Uma parte desses recursos é efetivamente aplicada na reforma agrária. Mesmo que o MST discorde dos números apresentados pelo governo e diga que são artificialmente inflacionados, não se pode negar que o número de famílias assentadas aumentou significativamente a partir de 1995. O MST consegue, dessa forma, alguns resultados positivos, e a sua principal arma, até agora, tem sido a pressão exercida por meio das ocupações. Apesar das ameaças do governo de que terras invadidas não serão desapropriadas, os estudos de Fernandes (1999) mostram ser possível estabelecer uma correlação positiva entre o número de ocupações e os assentamentos realizados.

Uma análise dos enfrentamentos entre o MST e o governo mostra que a luta pela reforma agrária dá origem a duas formas de pressão sobre o governo. A primeira forma é aquela exercida por sem-terra acampados e só se desfaz quando o assentamento é conquistado. Surge então o segundo tipo de pressão, aquele exercido pelos assentados para ter acesso aos créditos de reforma agrária, e viabilizar a produção até que o assentamento adquira autonomia suficiente para ser emancipado.

A tarefa do governo, portanto, não é nada fácil: é preciso romper o ciclo de pressão que se forma na ocupação, ou no assentamento. O sucesso do MST e a razão principal do seu crescimento podem ser explicados justamente pela sua habilidade em construir esses dois ciclos e mantê- 
los sempre ligados à organização do movimento, de modo que eles se reforcem mutuamente.

Agora é possível entender com maior clareza o motivo das ações do governo que se destinam a romper esses dois ciclos de pressão: cadastramento de famílias sem-terra interessadas em receber um lote em um assentamento de reforma agrária; proibição de desapropriações em terras ocupadas durante os dois anos subseqüentes à desapropriação; emancipação precoce dos assentamentos ou não-concessão de créditos aos mesmos, o que tem praticamente o mesmo resultado; tentativa de cooptação de lideranças com promessa de vantagens pessoais; repressão; criminalização do movimento; descentralização da reforma agrária, para evitar que a luta seja caracterizada como um enfrentamento entre o governo federal e o MST; e, por fim, o incentivo à divisão e ao surgimento de movimentos rivais. Em todas essas ações, o governo conta com um aliado fundamental, os meios de comunicação, que passamos a analisar a seguir.

\section{O MST E A IMPRENSA}

Não é preciso ser um observador muito atento para constatar que, quando o assunto é sem-terra, há consenso dos meios de comunicação a favor do governo. Sem querer diminuir a importância da televisão e do rádio, acreditamos ser possível limitar a nossa investigação à imprensa escrita, e, mais particularmente, aos jornais. O motivo para privilegiar os jornais, em relação às revistas, é que, a partir da análise dos editoriais, pode-se ter uma boa idéia do posicionamento de cada jornal diante das questões mais relevantes para o país. Consideramos importante, sobretudo, o fato de a pauta diária do noticiário dos órgãos de rádio e televisão ser sempre influenciada pelas matérias veiculadas na imprensa.

Ao comparar os editoriais que abordam temas relativos à reforma agrária e ao MST, nos quatro maiores jornais do país (Folha de S.Paulo, O Estado de S.Paulo, Jornal do Brasil, O Globo), constata-se que, no que diz respeito à questão agrária, não faz sentido a distinção entre jornais mais ou menos governistas. A presença do MST nos editoriais dos jornais mais importantes do país já constitui uma prova bastante conclusiva da sua relevância como ator político na cena nacional. Ao mesmo tempo que espelham os acontecimentos políticos de maior destaque, os editoriais fazem alertas ao governo e aos leitores, e comunicam a opinião oficial de cada jornal. Como, por exemplo, o editorial intitulado "O novo ator político", publicado no primeiro ano do governo de Fernando Henrique Cardoso, no jornal O Estado de S.Paulo (03/11/95): “(...) O Movimento dos Sem-Terra é hoje um ator de primeira grandeza na cena política quer pelo assentamento legal dos invasores, quer pela permanência deles nas terras ocupadas, quer pelo convencimento das autoridades públicas de que não se deve impor o respeito à lei, mas aceitar as invasões e negociar. Pelas razões acima expostas e outras mais, o fato é que a organização nacional do movimento conseguiu êxitos políticos inegáveis na sua política de invasão. As autoridades federais e estaduais, especialmente as primeiras, não se deram conta do dano que a acomodação diante das violações da lei poderia causar para todo o ordenamento jurídico do País, que assenta, gostemos ou não, sobre uma certa idéia de hierarquia e ordem.(...)".

Numa tentativa de quantificar a presença do MST em editoriais, pode-se contar o número dos dedicados ao movimento, e acompanhar a evolução dos resultados durante todo o governo Fernando Henrique Cardoso. Considerase que um editorial fala do MST quando cita explicitamente a sigla MST, ou se refere por extenso ao Movimento dos Trabalhadores Rurais Sem Terra, ou ainda, quando faz alusão a um líder do movimento, como José Rainha Júnior, ou a um acontecimento diretamente relacionado ao MST, como a Marcha a Brasília. Alguns editoriais tratam da reforma agrária ou da situação de agricultores sem-terra, mas não se referem diretamente ao MST. Nesse caso eles foram contabilizados como editoriais sobre a reforma agrária.

Como parâmetro de comparação, são considerados também os editoriais que aludem à Contag (Confederação Nacional dos Trabalhadores na Agricultura) e à CUT (Central Única dos Trabalhadores). A primeira foi escolhida porque é a maior organização de empregados rurais do Brasil, reunindo 25 federações estaduais e 3.630 sindicatos, incorporando 15 milhões de trabalhadores, ${ }^{1}$ enquanto a segunda é geralmente considerada, junto com o PT (Partido dos Trabalhadores), adversária constante do governo. Uma segunda razão para essa comparação é que, para o governo, seria bastante confortável que o MST se transformasse num sindicato nos moldes da Contag ou da CUT, com regras claras de atuação devidamente institucionalizadas. Os resultados foram agrupados na Tabela 1 e podem ser melhor analisados no Gráfico $1 .^{2}$

A interpretação desses resultados mostra que o MST vai progressivamente tomando o lugar da CUT como tema mais freqüente. Se nos anos de 1995, com a greve dos pe- 
GRÁFICO 1

Evolução do Número Total de Editoriais sobre o MST, a Reforma Agrária, a Contag e a CUT nos Principais Jornais do País Brasil - 1995-2000
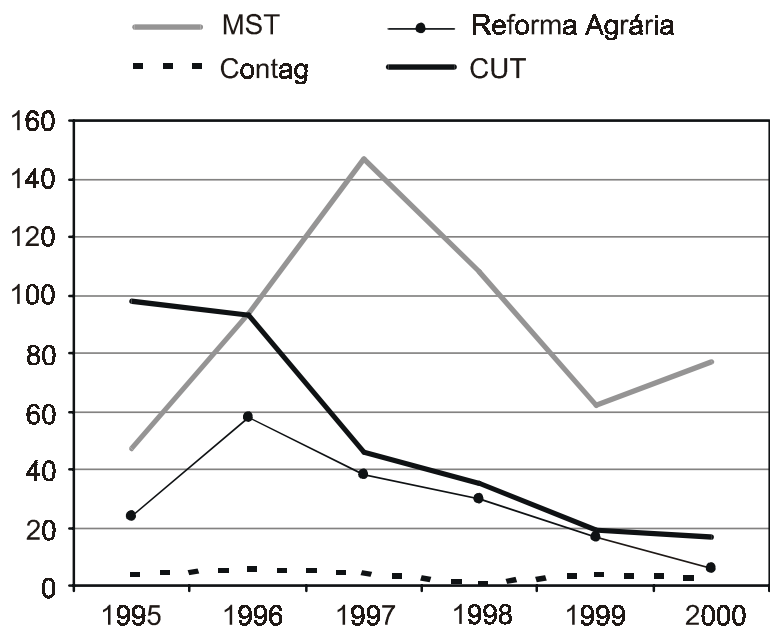

Fonte: Folha de S.Paulo; O Estado de S.Paulo; Jornal do Brasil; O Globo.

troleiros, e 1996, com a reforma da previdência social, a CUT teve presença assegurada nos editoriais desses jornais, nos anos seguintes a sua presença foi se tornando cada vez mais rara. Uma explicação pode ser a estratégia bem sucedida do governo de desmoralizar os movimentos sindicais ao reprimir duramente a greve dos petroleiros, de um lado, e de anular as pressões dos sindicatos no Congresso, com a aprovação da reforma da previdência, de outro.

Quanto ao MST, observa-se um pico no ano de 1997, que corresponde à Marcha a Brasília. Nos anos subseqüentes há uma diminuição progressiva do número de editoriais sobre o movimento. Mantém-se, contudo, um patamar significativo, principalmente quando comparado com os números correspondentes à Contag.

Outro dado interessante é que o tema reforma agrária apresenta um pico no ano de 1996, quando aconteceu o massacre de Eldorado dos Carajás e foi aprovada a nova lei sobre o ITR (Imposto Territorial Rural). Os problemas agrários eram comentados, mas não eram automaticamente relacionados com o MST que, nos anos seguintes, foi tomando conta do assunto.

Em suma, a identificação como adversário principal do governo, que antes era uma característica da CUT, passa a ser atribuída ao MST. Essa é, aliás, precisamente a análise feita por Luís Inácio Lula da Silva em novembro de 1995, quando afirmou que o MST exerce hoje o mesmo
TABELA 1

Evolução do Número Total de Editoriais sobre o MST, a Reforma Agrária, a Contag e a CUT nos Principais Jornais do País Brasil - 1995-2000

\begin{tabular}{lrrrrrr}
\hline Editoriais & 1995 & 1996 & 1997 & 1998 & 1999 & 2000 \\
\hline MST & 47 & 94 & 147 & 108 & 62 & 77 \\
Reforma Agrária & 24 & 58 & 38 & 30 & 17 & 6 \\
Contag & 4 & 6 & 5 & 1 & 4 & 3 \\
CUT & 98 & 93 & 46 & 35 & 19 & 17 \\
\hline
\end{tabular}

Fonte: Folha de S.Paulo; O Estado de S.Paulo; Jornal do Brasil; O Globo.

peso político para a esquerda brasileira que o movimento dos operários do $\mathrm{ABC}$ paulista teve no fim do regime militar. Lula admitiu, na ocasião, que a organização do MST na disputa pela terra forçou a direção dos partidos de esquerda a assumir a bandeira da reforma agrária ( $O$ Estado de S.Paulo, 03/11/95).

Uma análise mais detalhada mostra que, nos anos mais recentes, a CUT aparece, cada vez mais, associada ao MST nos editoriais. Em $O$ Estado de S.Paulo, por exemplo, no qual antes se lia "Estas manifestações têm em comum ser preparadas, conduzidas e feitas por pessoas ligadas ao PT, à CUT e ao PC do B, que se utilizam, como linha auxiliar, de movimentos sociais controlados ou infiltrados" ( $O$ Estado de S.Paulo, 18/05/97), lê-se agora "A reação de nativismo equivocado é compreensível quando vem de Lula e do baixo clero do PT, da CUT e do MST." (O Estado de S.Paulo, 02/08/98). Uma evolução parecida acontece com a Contag.

Faz-se necessário assinalar, ainda, que a aproximação da CUT e da Contag com o MST não acontece apenas no plano dos editoriais, a partir da identificação de maiores adversários do governo. Essa aproximação é real, e a CUT, que surgiu no meio bem urbano da indústria metalúrgica de São Bernardo do Campo, em 1983, se interessa cada vez mais pelos problemas rurais. ${ }^{3}$ A filiação da Contag à CUT, em abril de 1995, é um bom indício dessa nova tendência. O fato mereceu um editorial em $O$ Estado de S.Paulo (01/05/95), no dia do trabalho, que confirma a importância do acontecimento: "A adesão da Confederação Nacional dos Trabalhadores na Agricultura (Contag) à Central Única dos Trabalhadores (CUT) é tida e havida nos currais da CUT como o mais relevante fato do movimento sindical brasileiro em 30 anos. (...) Conquistar a Contag era um sonho alimentado pela CUT há anos."

A CUT também promove ações de solidariedade ao MST e realiza manifestações conjuntas com o movimento dos sem-terra. $\mathrm{O}$ fato mais significativo, no entanto, é a 
realização de ocupações de terra incentivadas pela CUT. Durante o mês de junho de 2000, o Departamento dos Trabalhadores Rurais da CUT promoveu 13 invasões em fazendas do Mato Grosso do Sul.

A Contag, por sua vez, também resolveu adotar uma linha de ação mais agressiva, e vem promovendo a ocupação de propriedades rurais, a exemplo do MST. Tratase de uma mudança significativa, para uma organização que, até este momento, preferia a negociação com base na sua grande representação sindical.

Nem é preciso falar que o governo acompanha com preocupação o fato de Contag e CUT passarem a defender a reforma agrária e a incluir ocupações de terra nas suas estratégias de ação. O Jornal do Brasil (24/04/99) cita o ministro-chefe da Casa Militar, general Alberto Cardoso: "Desde que a Contag se filiou à CUT, ela entrou na estratégia da violência, no sentido de praticar a invasão de terras. Esta competição entre as duas organizações é maléfica porque acirra os ânimos, fugindo de uma linha racional de discussão". O que o general esconde, e o jornal não menciona, contudo, é que o próprio governo incentiva a rivalidade entre as organizações que lutam pela reforma agrária, com o objetivo de diminuir a força do MST.

\section{TABELA 2}

Comparação entre o Número de Ocupações de Terras e o Número de Greves

Brasil - 1996-99

\begin{tabular}{lcc}
\hline Anos & $\begin{array}{c}\text { Número de } \\
\text { Ocupações de Terras }\end{array}$ & $\begin{array}{c}\text { Número } \\
\text { de Greves }\end{array}$ \\
\hline 1996 & 389 & - \\
1997 & 462 & (1) 563 \\
1998 & 446 & 580 \\
1999 & 495 & - \\
\hline
\end{tabular}

Fonte: Incra; Dieese.

(1) De maŗ̧o a dezembro.

TABELA 3

Características Organizacionais do MST, Contag e CUT

Brasil - 2000

\begin{tabular}{lcc}
\hline Entidades & Número de Filiados & Sindicatos \\
\hline MST & 420 mil famílias & (1) 2.000 \\
Contag & 15 milhões & 3.630 \\
CUT & 21 milhões & 3.088 \\
\hline
\end{tabular}

Fonte: MST; Contag; CUT.

(1) São 500 acampamentos +1.500 assentamentos.
Faz-se necessário notar que, ao se considerar o número de filiados a essas organizações, a Contag e a CUT são bem maiores do que o MST. Por outro lado, o número de ocupações de terras é comparável com o número de greves, como pode ser comprovado pelas Tabelas 2 e 3.

Ao confrontar esses dados e a freqüência com que tais organizações aparecem nos editoriais de jornal, pode-se fazer duas afirmações. Em primeiro lugar, a visibilidade de uma organização não depende do seu tamanho. Em segundo lugar, ocupações de terras têm chamado muito mais a atenção do que greves. Esse resultado já era esperado, pois as ocupações de terra e a defesa da reforma agrária vão de encontro ao sistema de propriedade privada, enquanto greves para a melhoria das condições de trabalho, o aumento dos salários ou a manutenção do emprego afetam apenas indiretamente o conjunto da população brasileira. Pode-se argumentar, também, que, por um lado, com a democratização, as greves deixaram de ser consideradas subversivas e, por outro, com a crise de emprego, o potencial de mobilização das greves diminuiu bastante. Dessa forma, acredita-se que o MST assumiu um lugar de destaque no imaginário das classes proprietárias e empresariais como o adversário que oferece perigo, ou seja, pode obrigar a uma mudança na organização da sociedade. O que acontece é que a luta pela reforma agrária assusta muito mais do que a luta sindical. Uma ocupação de terra é muito mais visível do que uma greve ou a ocupação de uma fábrica. E isso acontece porque o governo e as classes proprietárias já aprenderam a lidar com a luta sindical e a contorná-la, mas ainda não sabem muito bem o que fazer para enfrentar a luta pela reforma agrária.

Outra consideração, contudo, precisa ser feita. O senso de oportunidade do MST, ou seja, a habilidade que seus líderes têm em prever quais manifestações mobilizam mais a imprensa nacional, é um fator importante para a visibilidade do movimento nos meios de comunicação. O MST sempre organiza manifestações de massa, sejam elas marchas, acampamentos ou ocupações, pois, como afirmam seus líderes, essas são a melhor maneira de evitar a repressão aos manifestantes. O mais importante, contudo, é que cada passo sempre leva em conta o apelo jornalístico, pois os estrategistas do MST sabem muito bem que um acampamento à beira de uma rodovia tem muito mais visibilidade do que no interior das terras, do mesmo modo que montar um acampamento provisório em frente ao palácio do governo, ou diante de órgãos do governo ou agências bancárias, garante presença no noticiário da televisão e nos jornais. A ocupação de prédios públicos ou a 
concentração de militantes em frente à fazenda da família do Presidente da República, por sua vez, garante um lugar de destaque na imprensa, enquanto durar a mobilização.

O que incomoda mais o governo é a dificuldade em combater a habilidade que o MST demonstra em aparecer na mídia. Com efeito, seria muito mais confortável, para o governo, que o MST adotasse uma forma institucionalizada de oposição política. Já vimos, contudo, que, não somente os sindicatos não são uma alternativa atraente para o MST, como também eles começam a adotar as estratégias de ação próprias do movimento. Outra alternativa, bastante explorada pela oposição, é o caminho parlamentar e a organização em partidos políticos. Aliás, muitos se perguntam se esse não é o futuro do MST.

Interessa, portanto, verificar qual é a relação entre o MST e o Congresso.

\section{O MST E O CONGRESSO}

Uma prova incontestável da força política do movimento dos sem-terra é que ele não precisa, ou não quer, passar pela intermediação de um deputado para fazer com que suas reivindicações cheguem ao Executivo. De fato, os dirigentes do MST são recebidos diretamente pelo Presidente da República ou por seus ministros. Os parlamentares podem até facilitar o encontro, mas não são indispensáveis, o que vai contra a teoria da representação, de acordo com a qual os representantes do povo são os responsáveis por fazer chegar as reivindicações da população ao conhecimento do governo.

A situação mais comum é aquela em que alguns parlamentares, geralmente de oposição, oferecem-se para solucionar uma situação de impasse, entre o governo e o MST. Dessa forma, quando nenhum dos dois lados está disposto a fazer concessões, é freqüente ver parlamentares interessados num acordo se desdobrarem para marcar um encontro entre as duas partes. A atuação do Congresso nessa questão, no entanto, poderia ser muito maior. Com efeito, no que diz respeito às questões agrárias, o Congresso deixa as iniciativas para o Executivo. As leis que foram apreciadas desde 1995, como a que estabelece o rito sumário para fins de reforma agrária, ou a que introduziu mudanças no cálculo do Imposto Territorial Rural, foram propostas pelo presidente. A relativa facilidade com que essas leis foram aprovadas pelo Congresso fez o presidente afirmar que, "hoje, os latifundiários não passam de tigres de papel."
Não é uma tarefa fácil, contudo, determinar com precisão quem são os deputados e senadores que apóiam o MST, de um lado, e quem são aqueles que se opõem a esse movimento, de outro lado. Uma estimativa razoável consiste em identificar o apoio ao MST com os partidos de esquerda, e o seu repúdio com a direita. Se considerarmos como partidos de direita o PFL, o PPB, o PTB, o bloco PL-PSL, e o PSC, os adversários do MST no Congresso representariam, seguramente, mais de um terço dos parlamentares. Se considerarmos como partidos de esquerda o PT, o PDT, o PSB, o PC do B, o PPS e o PV, os deputados favoráveis ao MST representariam aproximadamente um quinto dos parlamentares, ou seja, a metade da direita. Dentro da oposição, o partido que oferece o apoio mais constante ao MST é o PT. Certamente, os deputados e senadores petistas se apresentam várias vezes como interlocutores entre o MST e o governo. Quanto aos parlamentares de partidos de centro, que podem ser identificados como sendo o PSDB e o bloco PMDB-PST-PTN, cuja bancada é um pouco maior do que a da direita, sua posição em relação ao MST é indefinida.

Outra linha de ação consiste em investigar quem são os parlamentares mais preocupados com as questões relativas à terra e à produção agrícola. Nesse grupo, há os que defendem os interesses dos grandes proprietários de terra e os que estão mais próximos da agricultura familiar. $\mathrm{O}$ primeiro grupo é freqüentemente rotulado como a "bancada ruralista". Sua origem remonta ao lobby exercido pela União Democrática Ruralista (UDR), durante a Assembléia Nacional Constituinte (1987/88), para impedir que a nova constituição facilitasse a realização de uma reforma agrária. ${ }^{4}$ Como mostrou o episódio da votação do rito sumário e do novo ITR, nas legislaturas mais recentes a bancada ruralista tem sido bastante enfraquecida. Ao responder a um jornalista do Jornal do Brasil, que indagava por que a bancada ruralista, com seus 150 parlamentares, se movimenta para combater a reforma agrária e negociar as dívidas dos agricultores, mas não aponta nem formula soluções para os problemas da agricultura, um grande fazendeiro e membro da Sociedade Rural Brasileira explicou que "o problema é que a bancada só é acionada para questões agudas, como dívida ou reforma agrária. Não para resolver problemas, mas para contorná-los." (Jornal do Brasil, 22/04/96).

Deve-se observar, contudo, que não é fácil estimar o tamanho da bancada contrária à reforma agrária. Um estudo recente identifica como membros da bancada ruralista, na atual legislatura, 83 deputados dos partidos PFL, 
PMDB, PSDB, PPB, PTB, PDT, PL, PSD, PMN, ou seja, $16,5 \%$ dos 513 deputados federais (Oliveira, 2000). Para a legislatura passada, outro estudo do mesmo autor citava 121 deputados como ruralistas (Oliveira, 1995). O próprio autor, contudo, ressalta a dificuldade em identificar um deputado como ruralista. No caso desses estudos, o critério utilizado foi a declaração do deputado sobre suas fontes de renda. $\mathrm{O}$ deputado foi considerado como componente potencial da bancada ruralista se entre as fontes de renda declaradas houvesse alguma forma de renda agrícola. Analisar os resultados das votações de interesse da bancada ruralista pode parecer uma boa idéia. O resultado, no entanto, seria falseado pois os interesses dos ruralistas são próximos aos dos representantes dos pequenos agricultores.

Faz-se necessário ressaltar, ainda, que o fato de um deputado pertencer à bancada ruralista não significa que ele seja contra a reforma agrária. Com efeito, Edélcio Vigna de Oliveira relata que, no início da legislatura de 1995, o Instituto de Estudos Sócio Econômicos (INESC) aplicou um questionário a todos os parlamentares sobre os temas mais polêmicos da agenda política nacional. Entre as perguntas elaboradas foi incluída uma questão sobre os conflitos de terra e a reforma agrária: "O que é necessário para inibir os conflitos agrários?”. O questionário foi respondido por 165 parlamentares. Mesmo sabendo que o número de entrevistados representa apenas um terço do total de congressistas, vale a pena observar os resultados: quase a metade dos que responderam apontou a reforma agrária como a melhor solução.

Como diz Oliveira (1995), "mais importante que a análise do quadro, é o resultado que aponta a reforma agrária como solução para o caso dos conflitos fundiários no país. Esse resultado indica que na Câmara dos Deputados, apesar da demonstração de força da bancada ruralista, há uma tendência que considera viável a implementação da reforma agrária como política pública. Essa colocação é necessária para que não se entenda o forte lobby dos ruralistas como um fato consumado contra as aspirações daqueles que propugnam pela democratização da terra." Naturalmente, os conflitos de terras podem ser mais prejudiciais para os fazendeiros do que a reforma agrária. Nas palavras de um grande fazendeiro do Paraná: "O problema chegou a este ponto, porque, em vez de negociar, quem cuida da reforma agrária no governo fez uma aposta no confronto. Veja o que aconteceu no Pontal do Paranapanema. Com a crise de hoje, com os preços das fazendas despencando por causa das invasões, seria muito fácil comprar aquelas terras e fazer os assentamentos. Por que o governo não propõe acordos? Porque há interesse no confronto. A incompetência e a demora do governo desaponta fazendeiros e os sem-terra. As soluções são prometidas, mas não ocorrem. O resultado é o radicalismo. Os fazendeiros vão buscar seus direitos na Justiça. Mas não temos interesse em agravar este problema. O MST é que tem interesse no problema. Nós temos interesse na solução dos conflitos fundiários, que nos trazem muita dorde-cabeça e desvalorizam as terras." (Jornal do Brasil, 22/04/96).

Por fim, da mesma forma que se pode falar numa bancada ruralista, é possível considerar a existência de uma bancada da reforma agrária, no Congresso. A edição de $O$ Globo (23/04/2000) informa que Adão Pretto (PT-RS), eleito graças aos votos de militantes do MST e de pequenos agricultores, foi o deputado federal que realizou a campanha mais barata, tendo recebido apenas $\mathrm{R} \$ 500 \mathrm{em}$ doações. Deve-se lembrar, ainda, a existência do núcleo agrário do PT, constituído por 16 deputados eleitos com uma base rural e favoráveis ao MST.

A despeito do potencial eleitoral demonstrado por alguns dos seus integrantes, o MST não acredita que a conquista de cadeiras no Congresso seja o melhor caminho para a luta pela reforma agrária. "O eixo da luta pela reforma agrária se deslocou do Parlamento para outros setores. (...) O tempo de lutar pela reforma agrária no Parlamento foi o da Constituinte," (Jornal do Brasil, 22/10/ 90) dizia João Pedro Stédile, em 1990. "Nunca desprezamos o caminho eleitoral. Vários de nossos militantes são deputados, prefeitos. Agora, as mudanças nesse país não vão se dar pelo Parlamento. O Parlamento é apenas ressonância da correlação de forças na sociedade e a correlação de forças na sociedade só vai mudar se os pobres forem para as ruas, se organizarem e lutarem contra o governo. Mas não devemos imaginar que o MST vá virar partido. O dia que virar, acabou com o movimento. Essa ilusão nunca tivemos nem queremos," (Jornal do Brasil, 21/05/2000) continua ele a dizer, hoje em dia. Na opinião dele, a organização e o fortalecimento do movimento são prioritários: "O senhor será candidato a deputado nas próximas eleições? Stédile: De jeito nenhum. A minha função é continuar a ajudar a construir o movimento dos semterra e lutar pela reforma agrária. Mas não desmereço o trabalho parlamentar e institucional. Ele é necessário, mas o fundamental é a organização de massas. Em toda a história da humanidade só o povo organizado em mobilização de massas fez mudanças profundas." (Veja, 06/08/97). 
Podemos afirmar, portanto, que o MST não despreza nem desmerece o trabalho parlamentar, embora ele não seja visto como prioritário. Os congressistas podem ser importantes intermediários quando é preciso resolver um impasse entre o movimento e o governo. Ademais, todo apoio é considerado bem-vindo, principalmente se faz parte de uma instituição reconhecida como interlocutor confiável na cena política. Esse parece ser, igualmente, o caso da Igreja, que passamos a analisar em seguida.

\section{O MST E A IGREJA}

A importância da Igreja como ator político, no Brasil, foi evidenciada durante o processo de redemocratização. Com efeito, no final dos anos 70 e começo dos 80 , todos os que lutavam contra o regime militar encontravam apoio em setores importantes da Igreja (Cava, 1988; Martins, 1994). O fato de a Igreja, tradicionalmente alinhada com as posições mais conservadoras das elites ao longo de toda a história do Brasil, ter-se empenhado na defesa da causa dos camponeses, a partir da década de 60 , pode parecer paradoxal. É preciso considerar, contudo, que naquele momento a Igreja se opunha ao comunismo. Tornava-se preferível, portanto, aproximar-se dos camponeses a vêlos transformados em revolucionários. Esse ponto é importante, pois a partir daquele momento, e mesmo que a parte mais progressista da Igreja fosse depois duramente combatida pelo governo militar, estavam lançadas as bases para que a Igreja viesse a ser considerada, hoje, um interlocutor confiável entre o governo e os trabalhadores rurais. Para o governo, sobretudo, trata-se de um interlocutor muito mais confiável do que os partidos de esquerda.

A Igreja apresenta uma vantagem decisiva, em relação aos partidos e aos sindicatos, quando se trata de organizar os trabalhadores do campo, pois, de acordo com José de Souza Martins (1986), a Igreja "tem um êxito muito grande na mobilização de populações camponesas, na criação de comunidades de base, etc. Acho que ela fala uma língua que é entendida pelas populações trabalhadoras, e é isso que a torna um elo essencial nas lutas populares no campo". De acordo com uma reportagem publicada na revista Veja (28/10/98), é justamente essa proximidade entre os padres e os trabalhadores rurais que explica a importância da Igreja na formação do MST: "O berço do movimento sem terra e o de boa parte dos padres é o mesmo: as cidades mais pobres do interior dos Estados do Sul. Segundo uma pesquisa feita neste ano pelo Centro de Es- tatística Religiosa e Investigações Sociais - Ceris, quase a metade do clero brasileiro veio da Região Sul do país. Dois terços pertencem a famílias de classe baixa ou média-baixa. Enquanto $78 \%$ da população brasileira vive nos centros urbanos, $64 \%$ do clero tem origem na zona rural. Três em cada quatro padres nasceram em cidades com menos de 20 mil habitantes".

Outros dois aspectos marcaram decisivamente a influência da Igreja sobre o MST. O primeiro deles é o caráter ecumênico da Comissão Pastoral da Terra (CPT), que evitou que a luta pela terra se fracionasse em várias organizações. ${ }^{5} \mathrm{O}$ segundo, também a característica mais importante da CPT, é a capilaridade dessa entidade nas camadas populares, principalmente no campo e sobretudo nas áreas de fronteira, onde ocorre a maioria dos conflitos de terras. Daí sua posição privilegiada quando se trata de quantificar com precisão o número de assassinatos no campo, os conflitos agrários ou as ocupações de terras (Martins, 1985).

O apoio da Igreja à reforma agrária não se limita, contudo, à sistematização e denúncia de dados sobre conflitos no campo. O apoio logístico também é muito importante, como por exemplo o que foi oferecido ao MST durante a Marcha a Brasília, em 1997, quando a Igreja Católica permitiu a hospedagem em igrejas e casas paroquiais durante todo o trajeto, além de auxiliar na arrecadação de alimentos para os manifestantes. Outro apoio material importante, conseguido por meio das conexões que a Igreja tem no exterior, é a ajuda financeira oferecida por organizações cristãs internacionais. Estima-se que cerca de $15 \%$ dos recursos do MST sejam provenientes dessa rede de solidariedade internacional ( $O$ Estado de S.Paulo, 01/06/98).

Feitas essas considerações, pode-se dizer que é possível distinguir dois grupos distintos entre os eclesiásticos brasileiros: os progressistas e os conservadores. Os primeiros, em grande parte adeptos da Teologia da Libertação, costumam posicionar-se a favor da reforma agrária e das lutas operárias, enquanto os segundos condenam estas atitudes e permanecem fiéis às determinações do Vaticano (Moura, 1981; Gusmão, 1981).

Naturalmente, o governo brasileiro tem considerado com preocupação o envolvimento dos bispos progressistas com as causas populares e, em especial, com a luta pela reforma agrária. A reação mais freqüente tem sido a tentativa de obter do papa João Paulo II, conhecido por sua posição conservadora quando o assunto são os movimentos sociais, alguma manifestação a favor da ordem e 
contra o envolvimento político de padres e militantes católicos.

Em 1985, José Sarney esteve com o papa João Paulo II, no Vaticano. O ex-governador paulista Abreu Sodré, alarmado com o surgimento do MST, alertara o então Presidente da República para o perigo potencial de um levante no campo. Sarney pediu então ao Itamaraty que organizasse uma viagem a Roma cujo objetivo principal era pedir ao papa que desautorizasse os setores da Igreja comprometidos com a reforma agrária. A missão, no entanto, resultou num retumbante fracasso. De acordo com o depoimento de Rubens Ricupero, ${ }^{6}$ que na qualidade de assessor especial da Presidência acompanhou Sarney nessa viagem, não somente o papa se recusou a se manifestar publicamente contra os padres que militavam junto com trabalhadores rurais, mas também, durante a missa em homenagem ao povo brasileiro, os textos escolhidos trataram da função social da terra, além de outros que tinham sido escritos por D. Hélder Câmara para a Campanha da Fraternidade. Na saída da celebração, um jornalista que acompanhava a delegação brasileira, numa atitude inteiramente não-protocolar, interpelou o sumo pontífice indagando se ele tinha uma última mensagem para os brasileiros. "Sim", respondeu o papa, voltando-se para o jornalista e falando em português, "desejo que se dê mais atenção aos pobres do Brasil e que se faça a reforma agrária".

A posição do papa no que diz respeito à questão agrária no Brasil é a de que é preciso fazer a reforma agrária, mas sem desrespeitar o direito de propriedade. O Vaticano entende como justas as reivindicações do MST, apesar de não apoiar os seus métodos de ocupar propriedades particulares e agências bancárias para forçar o governo a liberar créditos. A Igreja prefere uma reforma preventiva, com o objetivo de evitar que a luta pela terra se transforme em movimento revolucionário, a uma reforma confiscatória e radical, mais afinada com os princípios socialistas. Daí os apelos do papa para que a reforma agrária seja feita de acordo com a lei.

Esse ponto de vista não impediu, contudo, que, uma semana após o massacre de Eldorado dos Carajás, o papa enviasse à CNBB uma carta na qual condena o massacre de sem-terra no Pará e pede uma reforma agrária “corajosa e de longo alcance" (Folha de S.Paulo, 25/04/96). A resposta do governo foi insistir na tradicional posição de tentar conseguir um posicionamento mais firme, por parte do Vaticano, contra os movimentos sociais e os bispos progressistas, de modo a reforçar a identidade entre o clero conservador e o papa. O que se deve evitar a todo custo, para o governo brasileiro, é que a luta pela terra resulte na união das duas tendências da Igreja, forçando o governo a se envolver de maneira mais séria com a questão agrária. Como parte desses esforços, deve-se considerar a visita oficial de Fernando Henrique Cardoso ao Vaticano, em 14 de fevereiro de 1997, além das cinco viagens a Roma empreendidas pelo ministro da Reforma Agrária, Raul Jungmann, para prestar contas pessoalmente ao papa sobre o andamento da reforma agrária no país. Essas viagens revelam, também, uma questão fundamental: a importância que o governo atribui à opinião pública, principalmente internacional, quando o assunto é o MST.

\section{O MST E A OPINIÃO PÚBLICA}

No caso específico do MST, a opinião pública tem se revelado um elemento importante para as decisões do governo e também para tomadas de posição de representantes no Legislativo. Podemos distinguir duas realidades separadas: de um lado, temos a opinião pública nacional, do outro, a opinião pública internacional. No segundo caso, talvez seja mais correto falar em imagem do governo brasileiro no exterior.

No que diz respeito à opinião pública nacional, é preciso considerar que, numa sociedade majoritariamente urbana como a sociedade brasileira contemporânea, as lutas do campo só conseguem se projetar nacionalmente se tiverem o respaldo e o reconhecimento da população das cidades. Com efeito, os moradores de áreas rurais representam apenas um quinto da população brasileira. Dessa maneira, os $80 \%$ restantes que moram em áreas urbanas são decisivos para o futuro de qualquer movimento agrário. Da mesma forma que o MST tem consciência que apenas com os votos de áreas rurais não é possível mudar a correlação de forças na Câmara dos Deputados ou no Senado, seus dirigentes sabem perfeitamente que o apoio da população urbana é fundamental para sua luta. Daí a importância de atos e manifestações nas cidades. Realizamse marchas pelas estradas e grandes avenidas das capitais, organizam-se manifestações e acampamentos em frente às sedes do poder público (Incra, Palácio do Governo) ou diante de agências bancárias que estejam supostamente retendo os créditos destinados à reforma agrária. Os locais são estrategicamente escolhidos de forma a garantir a maior visibilidade possível, porém sem atrapalhar o cotidiano da cidade. Do ponto de vista dos dirigentes do MST, trata-se de conscientizar, e não de atrapalhar. De fato, raramente vêem-se militantes do MST 
bloqueando uma avenida ou impedindo funcionários públicos de entrar no seu local de trabalho. Quando se diz que o MST invadiu prédios públicos, na maioria das vezes os manifestantes estão ocupando a entrada ou o saguão principal do prédio para forçar uma audiência com as autoridades responsáveis.

O objetivo principal das manifestações nas cidades é fazer conhecer as suas reivindicações e conseguir o apoio das populações urbanas à causa da reforma agrária. $\mathrm{O}$ apoio do MST às lutas urbanas, como manifestações pelo aumento do salário mínimo, passeatas de professores ou servidores da saúde pela melhoria das condições de trabalho, greves organizadas pelas centrais sindicais, ou até mesmo passeatas de policiais por melhores salários, é considerado uma forma de solidariedade entre trabalhadores. Daí as manifestações públicas de incentivo aos movimentos populares urbanos da parte de alguns dirigentes do MST, e que são interpretadas pela imprensa como a prova de que o movimento não está interessado apenas na reforma agrária, mas também na revolução e na agitação política.

Pesquisas de opinião pública realizadas ao longo dos últimos anos mostram que o MST conta com o apoio da maioria da população brasileira. $\mathrm{O}$ apoio à reforma agrária varia entre $80 \%$ e $94 \%$, enquanto aproximadamente dois terços da população considera o MST um movimento legítimo. Durante a marcha do MST a Brasília, em 1997, a popularidade do movimento esteve no seu auge, chegando a $77 \%$ de apoio.

Uma ressalva faz-se necessária, contudo, pois apesar de grande parte da população brasileira ser favorável à reforma agrária, ela não está disposta a tomar iniciativas que a viabilizem, seja porque não a considera uma prioridade absoluta, seja porque não tem uma idéia clara do que é uma reforma agrária. No primeiro caso, de acordo com o qual a reforma agrária não é considerada prioridade, é importante lembrar que a questão da escravidão só foi resolvida no Brasil quando passou a bloquear o desenvolvimento de uma indústria nacional. No segundo caso, é preciso considerar que há vários projetos de reforma agrária, e que todos os que se dizem favoráveis a ela não concordam necessariamente com a reforma agrária pretendida pelo MST. Esse é, precisamente, o entendimento de Martins (1997): "Não basta a opinião pública dizer-se favorável à reforma agrária. Você faz pesquisa de opinião e descobre que $70 \%$ das pessoas são favoráveis à reforma agrária. Só que elas não sabem o que é reforma agrária. Tanto que, na hora de votar, votam em partidos e pessoas que, por razões de classe social e de opção ideológica, são contrárias a essa reforma. Esses partidários da reforma não condicionam seu voto à adoção da reforma agrária como plataforma política daqueles que elegem".

É necessário ressaltar que várias cartas de leitores e artigos assinados, publicados em jornais e revistas, sugerem que uma grande parte da população tem uma idéia romântica do que seja uma reforma agrária. De acordo com essa visão, o homem do campo ainda é considerado um personagem simples, modesto, apático e preguiçoso, que precisa ser protegido, à imagem do personagem Jeca Tatu, de Monteiro Lobato (Lobato, 1998). Assim, não são poucas as manifestações que consideram os sem-terra o resquício de um Brasil arcaico, ou que identificam na atuação política do MST um desvirtuamento do movimento. A questão fundamental que se coloca para o MST é, portanto, saber como o movimento vai fazer para enfrentar o desafio de transformar a simpatia que angaria da população em apoio permanente. $O$ futuro do movimento depende da sua capacidade de conseguir convencer a opinião pública nacional de que a sua atuação política é, não somente legítima, mas também a própria essência do movimento. De nada adianta, dessa perspectiva, apoiar humanamente e caridosamente a reforma agrária se a atuação política dos sem-terra for condenada. Uma parcela importante da população brasileira ainda parece concordar com a opinião da burguesia francesa do começo do século XIX a respeito do homem do campo, como foi retratada por Balzac (1961): "se, politicamente, as suas agressões devem ser impiedosamente reprimidas, humanamente e religiosamente, ele é sagrado".

Resta ainda tratar da repercussão internacional do MST. O movimento foi objeto de diversas reportagens em grandes jornais estrangeiros, periódicos e emissoras de televisão, sobretudo depois do massacre de Eldorado dos Carajás, noticiado em 61 idiomas (IstoÉ, 24/04/97). Uma conseqüência imediata à condenação internacional de Eldorado dos Carajás foi o cancelamento de uma viagem do presidente a Washington, por temer protestos e manifestações por parte de defensores dos direitos humanos (O Globo, 27/04/96). A marcha dos sem-terra a Brasília teve como resultado aumentar ainda mais o interesse no assunto, como testemunha o ministro da Saúde, José Serra: "A marcha a Brasília comandada pelo MST elevou ao máximo a simpatia internacional pelos pobres brasileiros. Acrescentou, nos países desenvolvidos, um quarto ponto na agenda de suas preocupações com o Brasil, até há pouco centralizada em três questões: índios, direitos humanos e meio ambiente" (Fo- 
lha de S.Paulo, 21/04/97). O MST tem consciência da importância desse apoio externo e da sua influência no tratamento dispensado ao movimento pelo governo. Por isso, dedica um cuidado particular aos contatos com organizações não-governamentais internacionais e envia vários de seus militantes ao exterior.

Como se pode verificar, o MST não ocupa apenas terras e prédios públicos, mas ocupa também reuniões de ministros, discursos do presidente, relatórios dos serviços de inteligência, editoriais de jornais, manchetes nos noticiários, pronunciamentos de parlamentares, conversas entre o presidente e o papa, pesquisas de opinião pública e até protestos nas visitas do presidente ao exterior. Foi possível provar que o MST cresceu e se expandiu durante a presidência de Fernando Henrique Cardoso, mas o governo só percebeu a força do movimento em 1997, a partir da Marcha a Brasília. De fato, naquele ano o MST esteve no auge, e podemos dizer que foi a partir daí que o movimento se tornou definitivamente um ator político: nos seus discursos o presidente passou a se referir explicitamente ao movimento, os editoriais de jornais passaram a tratar periodicamente do MST e a reforma agrária contava com o apoio de $94 \%$ da população.

Quatro anos depois, no entanto, o MST enfrenta grandes dificuldades, desde que o governo resolveu cortar os créditos aos assentados. Mesmo que um cenário pessimista venha a se confirmar e o movimento venha a ser completamente desmantelado, contudo, a experiência das suas lutas e das conquistas provocará conseqüências. Não podemos esquecer que são 400 mil famílias, aproximadamente um milhão e meio de pessoas. Nas palavras de um jovem militante, "a maior revolução é dentro da nossa cabeça".

\section{NOTAS}

E-mail do autor: brunaao@hotmail.com

Este artigo é uma versão resumida da dissertação de mestrado do autor (Comparato, 2001), sob orientação da Professora Doutora Maria Teresa Sadek.

1. A Contag foi criada em 22 de dezembro de 1963, no Rio de Janeiro, reunindo 14 federações e 475 sindicatos de trabalhadores rurais. $O$ reconhecimento oficial da Contag ocorreu no dia 31 de janeiro de 1964, por meio do Decreto Presidencial n ${ }^{\circ}$ 53.517. O golpe militar de 1964 resultou na intervenção da entidade e na prisão e exílio de vários dirigentes. O MSTR retomou a entidade em 1968, derrotando o interventor. A Contag realizou sete congressos nacionais de trabalhadores e trabalhadoras rurais, sendo o último em 1998, no qual foi eleita a atual diretoria da entidade. A Contag representa os interesses dos trabalhadores e trabalhadoras rurais assalariados, permanentes ou temporários; dos agricultores familiares, proprietários ou não, dos sem-terra e, ainda, daqueles que trabalham em atividades extrativistas. Essas e outras informações sobre a Contag podem ser obtidas na página que a Contag mantém na internet, no endereço: http://www.contag.org.br

2. Os resultados foram agrupados para resumir a exposição. A evolução da quantidade de editoriais sobre os temas considerados é muito semelhante para os quatro jornais. Em média, aproximadamente uma vez por semana é publicado um editorial sobre um desses temas em cada um dos jornais. Para ter acesso aos dados completos, para cada jornal, consultar Comparato, 2001.

3. Em “O 'novo sindicalismo' na transição brasileira”, Keck (1988) mostra que a CUT teve um papel importante no processo de transição para a democracia, no Brasil. Os sindicatos rurais e a Contag não ocupam um lugar de destaque nas análises sobre aquele momento político, que privilegiam os movimentos urbanos e a fundação do PT. É interessante notar, contudo, que foi justamente nessa época que surgiu o MST.

4. Desmobilizada após a aprovação da Constituição de 1988 e a derrota de Ronaldo Caiado nas eleições presidenciais de 1989, a UDR ressurgiu em 1996 para enfrentar os avanços do MST na região do Pontal do Paranapanema, em São Paulo. Na mesma época também reapareceu o obscuro Movimento Direita Volver (MDV), integrado por antigos militantes do Comando de Caça aos Comunistas (CCC) e que mantém ligações com a Tradição Família e Propriedade (TFP), Jornal do Brasil (22/09/96).

5. Segundo as informações fornecidas pela página que essa entidade mantém na internet, a Comissão Pastoral da Terra (CPT) foi criada em 1975 com o objetivo de assessorar sindicatos, associações de pequenos produtores, movimentos sociais e outras iniciativas populares, prestando-lhes assessoria pastoral, teológica, metodológica, jurídica, política e sociológica. A CPT colabora diretamente com a Igreja Católica e a Igreja Evangélica de Confissão Luterana no Brasil, atuando em conjunto com muitas dioceses, paróquias e comunidades eclesiais.

6. Depoimento dado ao autor em novembro de 2000.

\section{REFERÊNCIAS BIBLIOGRÁFICAS}

BALZAC, H. La comédie humaine VIII - études de moeurs: scènes de la vie de Campagne - les paysans. Paris, Gallimard, 1961.

CANDIDO, A. Os parceiros do Rio Bonito. São Paulo, Duas Cidades, 1998.

CAVA, R.D. “A Igreja e a abertura, 1974-1985”. In: STEPAN, A. (org.). Democratizando o Brasil. São Paulo, Paz e Terra, 1988, p.231-73.

COMPARATO, B.K. A ação política do MST. Dissertação de Mestrado. São Paulo, Faculdade de Filosofia, Letras e Ciências Humanas (FFLCH) da USP, 2001.

CUNHA, E. Os sertões. Rio de Janeiro, Francisco Alves, 1979.

FERNANDES, B.M. A formação do MST no Brasil. Petrópolis, Vozes, 1999

GUSMÃO, S.B. "Novos espaços na velha estrutura". In: SALEM, H. (org.). A Igreja dos oprimidos. São Paulo, Brasil Debates, 1981.

KECK, M.E. "O novo sindicalismo na transição brasileira". In: STEPAN, A. (org.). Op. cit., 1988.

LOBATO, M. Urupês. São Paulo, Brasiliense, 1998.

MARTINS, H.H.T. Igreja e movimento operário no $A B C$. São Paulo, Hucitec, 1994.

MARTINS, J.S. "Na revolta das formigas". In: CASALDÁLIGA, D.P. (org.). Conquistar a terra, reconstruir a vida, CPT-dez anos de caminhada. Petrópolis, Vozes, 1985.

A reforma agrária e os limites da democracia na "Nova República". São Paulo, Hucitec, 1986.

1995
. Os camponeses e a política no Brasil. Petrópolis, Vozes, 
"A questão agrária brasileira e o papel do MST". In: STÉDILE, J.P. (org.). A Reforma agrária e a luta do MST. Petrópolis, Vozes, 1997.

MONTEIRO, D.T. Os errantes do novo século. São Paulo, Duas Cidades, 1974.

MOURA, A.C. "A CNBB e o compromisso com o povo". In: SALEM, H. (org.).Op. cit., 1981
OLIVEIRA, E.V. A bancada ruralista na Câmara dos Deputados - análise preliminar: conceito, força e fraqueza. Brasília, Inesc, 1995.

. A bancada ruralista - legislatura 1999/2002. Brasília, Inesc, 2000.

QUEIROZ, M.I.P. O messianismo no Brasil e no mundo. São Paulo, Dominus, 1965.

. Os cangaceiros. São Paulo, Duas Cidades, 1977. 